\title{
ANALISA SISTEM DISTRIBUSI AIR PDAM DI DESA PEMONGKONG KEC. JEROWARU KAB. LOMBOK TIMUR
}

\author{
Muhamad Hilmi, Rudy Sutanto, Yesung Allo Padang \\ Jurusan teknik Mesin Fakultas Teknik Universitas mataram
}

\begin{abstract}
Abstrak
Dalam proses pendistribusian air bersih ke desa Pemongkong, sering terjadi kekurangan debit di beberapa dusun, sehingga pada penelitian ini akan dicari faktor apa saja yang menyebabkan debit aliran pada beberapa dusun sangat rendah.

Secara umum kebutuhan masyarakat masih dapat terpenuhi. Hal ini dapat dilihat dari kebutuhan rata-rata (debit demand) harian berdasarkan SKAB DPU sebesar 9,96 L/s, sedangkan debit yang tersedia di sumber dari bulan Januari s/d Agustus 2012 lebih dari 9,96 L/s. Kemudian terjadi penurunan debit mulai bulan Oktober s/d Desember 2012, sehingga kebutuhan masyarakat tidak dapat terpenuhi. Sedangkan pada jam puncak beberapa dusun mendapatkan debit aliran yang sangat rendah, bahkan tidak mendapatkanya sama sekali. Hal ini disebabkan karena keterbatasan debit yang disediakan oleh sumber, dimana debit maksimum yang dihasilkan oleh sumber sebesar 12,4 L/s, sedangkan kebutuhan pada jam puncak mencapai 22,09 L/s.

Selanjutnya untuk analisa head loss dan head tekan sisa, pada jam puncak untuk pemakaian maksimum (bulan Pebruari 2012) terdapat dua dusun yang mengalami head tekan sisa yang cukup rendah dibandingkan dengan dusun yang lain. Kedua dusun tersebut yaitu di dusun Ujung berdasarkan perhitungan manual sebesar 20,15 m, dan berdasarkan simulasi Epanet 2.0 sebesar 21,94 m, sedangkan di dusun Permas berdasarkan perhitungan manual sebesar -2,81 m dan berdasarkan simulasi Epanet 2.0 sebesar -1,50 m. Hal ini menyebabkan potensi hambatan aliran menuju kedua dusun tersebut cukup tinggi, dan aliran cendrung akan menuju tempat di mana Head Tekan sisa yang lebih tinggi. Permasalahan ini dapat diatasi dengan memperbesar diameter pipa transmisi yang menuju kedua dusun tersebut dari 2 in menjadi 3 in. Head tekan sisa yang dihasilkan setelah menggunakan diameter pipa 3 in adalah di dusun ujung berdasarkan perhitungan manual sebesar 111,31 m, dan berdasarkan simulasi Epanet 2.0 sebesar 112,45 m, sedangkan di dusun Permas berdasarkan perhitungan manual sebesar 102,72 m dan berdasarkan simulasi Epanet 2.0 sebesar 103,01 m.
\end{abstract}

Kata kunci : Debit tersedia, Debit demand, Head tekan sisa, Epanet 2.0.

\section{Abstract}

In the process of the distribution of clean water to a village Pemongkong, debit frequent shortages in some villages, so this study will look at what factors cause the flow rate is very low in some villages.

Generally, public needs can still be met. It can be seen from the average requirement (debit demand) daily by SKAB DPU of $9.96 \mathrm{~L} / \mathrm{s}$, while the available flow at the source from January-August 2012 more than $9.96 \mathrm{~L} / \mathrm{s}$. Then a decline debit from September-December 2012, so that people's needs can not be met. Nevertheless, at the peak hours several subvillage get very low flow rates. This is because the discharge limitations provided by the source, where the maximum discharge generated by the source of $12.4 \mathrm{~L} / \mathrm{s}$, while the demand at the peak hours is $22.09 \mathrm{~L} / \mathrm{s}$.

Further analyzes about head loss and preesure residu, at peak hours for maximum usage (February 2012) there are two sub-villages that experienced head press remaining fairly low compared to other sub-villages. These sub-villages are Ujung of 20,15 m and Permas of -2,81 $m$. This leads to a potential barrier to the flow of these sub-villages is quite high, and water will tend to flow towards the place where the head pressure residual higher. This problem can be overcome by increasing the transmission diameter pipe from 2 ince to 3 ince. This problem can be overcome by increasing the diameter of the transmission pipeline to both the village of 2 to 3in ince. Head hit the rest is generated after using the 3-in-diameter pipe is in the end based on manual calculations hamlet of $111.31 \mathrm{~m}$, and based on simulations Epanet 2.0 at $112.45 \mathrm{~m}$, 
while in the hamlet Permas based on manual calculations of $102.72 \mathrm{~m}$ and based on simulation Epanet 2.0 at $103.01 \mathrm{~m}$.

Key words : Discharge, Debit demand, Pressure residu, Epanet 2.0.

\section{PENDAHULUAN}

Air merupakan unsur yang vital dalam kehidupan manusia. Seseorang tidak dapat bertahan hidup tanpa air. Jika kita tinjau lebih luas lagi, penggunaan air bukan hanya untuk mempertahankan hidup, melainkan untuk memenuhi kebutuhankebutuhan lain seperti mandi, mencuci, memasak, irigasi dll. Dengan melihat keadaan tersebut, maka pantaslah kita menyatakan bahwa air merupakan salah satu penopang utama bagi kehidupan manusia.

Di antara kebutuhan-kebutuhan masyarakat terhadap air, jenis air yang paling dibutuhkan adalah air bersih. Kebersihan ini berkaitan dengan masalah kesehatan masyarakat sebagai pengguna air tersebut. Jika air yang digunakan untuk keperluan konsumsi tidak bersih dan steril dari bakteri, maka air yang mengandung bakteri tersebut dapat menyebabkan timbulnya penyakit.

Kaitannya dengan hal tersebut, pemerintah tentu tidak lepas tangan dan berusaha memberikan pasokan air bersih kepada masyarakat. Usaha pemerintah untuk memenuhi kebutuhan masyarakat terhadap air bersih dapat di lihat dari pembentukan lembaga-lembaga yang mengurusi proses pengolahan sampai pendistrubusian air bersih tesebut.

Namun sampai saat ini, air bersih yang didapatkan oleh masyarakat umum masih sangat minim. Hal ini tentu saja disebabkan oleh banyak faktor. Salah satu faktor yang menghambat proses distribusi air bersih ke masyarakat adalah sistem distribusi air tersebut. Sistem distribusi air bersih ini sangatlah erat kaitannya dengan sistem perpipaan, karena proses pendistribusian air bersih ke masyarakat secara umum dilakukan melalui saluran pipa dengan memanfaatkan aliran dalam pipa tersebut.

Desa Pemongkong Kec. Jerowaru kab. Lombok Timur merupakan salah satu desa yang sumber utama air bersihnya dari PDAM (Perusahaan Daerah Air Minum). Akan tetapi dalam proses pendistribusian air bersih tersebut, masih terjadi permasalahan yang perlu dicarikan solusinya. Di beberapa dusun, kadang-kadang masyarakat mendapatkan debit aliran yang sangat rendah dan bahkan tidak mendapatkannya sama sekali. Melihat permasalahan ini, sangat perlu dilakukan penelitian untuk mengetahui penyebab dari permasalahan tersebut, yang selanjutnya diharapkan bisa mendapatkan solusi untuk mengatasi permasalahan itu sendiri.

Dusun-dusun yang terlayani menggunakan jaringan perpipaan dapat dilihat pada tabel 1 .

Tabel 1. Jumlah pelanggan dan sambungan umum di masing-masing dusun.

\begin{tabular}{|c|l|c|c|l|c|}
\hline No & \multicolumn{1}{|c|}{ Dusun } & Node & $\begin{array}{l}\text { Jumlah Pelanggan } \\
\text { Domestik } \\
\text { (KK) }\end{array}$ & $\begin{array}{l}\text { Non } \\
\text { Domestik } \\
\text { Sambu- } \\
\text { ngan }\end{array}$ \\
\hline 1 & Pengoros & 7 & 13 & 1 Masjid & 0 \\
\hline 2 & Permas & 8 & 102 & 1 Masjid & 3 \\
\hline 3 & Serumbung & 9 & 112 & $\begin{array}{l}1 \text { Masjid \& } \\
2 \text { SD/M }\end{array}$ & 5 \\
\hline 4 & Keranji & 10 & 40 & 1 SD & 2 \\
\hline 5 & Ujung & 11 & 100 & 1 Masjid & 5 \\
\hline 6 & Pemongkong & 12 & 66 & $\begin{array}{l}1 \text { Masjid \& } \\
2 \text { SD/MI }\end{array}$ & 5 \\
\hline 7 & Ujung Betok & 13 & 7 & 0 & 3 \\
\hline 8 & Jelok Buso & 14 & 44 & 1 SMK & 5 \\
\hline 9 & Desa Sepit ${ }^{*}$ & 15 & 189 & $\begin{array}{l}2 \text { Masjid \& } \\
2 \text { SD/MI }\end{array}$ & 6 \\
\hline \multicolumn{7}{|c|}{ Jumlah } & 673 & 15 & 36 \\
\hline
\end{tabular}

Sumber: PDAM Lombok Timur

\section{LANDASAN TEORI}

\section{A. Mekanika Fluida}

Mekanika fluida merupakan bidang ilmu yang membahas tentang fluida, baik fluida gas maupun cairan. Ruang lingkup pembahasan dalam Mekanika Fluida secara Umum ada dua yaitu Statika Fluida dan Dinamika Fulida.

\section{Statika Fluida}

Statika fluida merupakan bagian dari mekanika fluida yang membahas tentang sifat-sifat dari fluida diam atau biasa disebut fluida statis.
a. Tekanan
Tekanan didefinisikan sebagai gaya persatuan luas. Tekanan dapat 
dinyatakan dalam:

$$
\begin{aligned}
& \mathrm{P}=\frac{\mathrm{F}}{\mathrm{A}} \\
& \text { Dimana: } \\
& \mathrm{p}=\text { Tekanan }\left(\mathrm{N} / \mathrm{m}^{2}\right) \\
& \mathrm{F}=\text { Gaya Tekan }(\mathrm{N}) \\
& A=\text { Luas Bidang Tekan }\left(\mathrm{m}^{2}\right)
\end{aligned}
$$

b. Tekanan Hidrostatis

Tekanan Hidrostatis merupakan tekanan suatu dalam suatu fluida yang disebabkan oleh berat dari fluida itu sendiri.Tekanan Hidrostatis dapat dirumuskan menjadi:

$$
\begin{aligned}
& \mathrm{P} h=\rho \mathrm{gh}(\mathrm{Pa}) \\
& \text { Dimana: } \\
& \mathrm{p}_{\mathrm{h}}=\text { Tekanan Hidrostatis }\left(\mathrm{N} / \mathrm{m}^{2}\right) \\
& \rho=\text { Massa Jenis }\left(\mathrm{kg} / \mathrm{m}^{3}\right) \\
& g \text { = Percepatan Gravitasi }\left(\mathrm{m} / \mathrm{s}^{2}\right) \\
& \mathrm{h}=\text { Ketinggian pengukuran }(\mathrm{m})
\end{aligned}
$$

\section{c. Tekanan Uap}

Tekanan uap merupakan tekanan dimana fluida cair (liquid) mulai berubah fase dari fase cair menjadi fase uap. Pada temperatur tertentu, suatu zat cair akan mendidih apabila tekanannya mencapai tekanan uap meskipun temperaturnya konstan.

Didalam fluida yang mengalir, tekanan pada suatu titik tertentu mungkin mencapai tekanan uapnya sehingga pada titik tersebut akan terjadi penguapan. Peristiwa ini disebut dengan kavitasi. Efek dari kavitasi ini berupa kerusakan pada material atau peralatan yang berada di sekitaran terjadinya kavitasi.

\section{Dinamika Fluida}

Dinamika fluida merupakan bagian dari mekanika fluida yang membahas tentang kecepatan, percepatan dan gaya-gaya yang bekerja pada gerakan fluida. Gerakan fluida umumnya berupa aliran pada suatu medium tertentu. Salah satu contohnya adalah aliran dalam pipa.

\section{B. Aliran dalam Pipa}

1. Konsep Dasar Aliran Fluida

a. Persamaan Kontinuitas

Persamaan kontinu dapat dinyatakan dalam:

$$
\left.\rho_{1} A_{1} V_{1}=\rho_{2} A_{2} V_{2} \ldots \ldots \ldots \ldots \ldots . . . . . .4 a\right)
$$

Karena dalam aliran pipa diasumsikan tidak ada perubahan temperatur, maka massa jenis fluida dianggap konstan dari titik 1 ke titik 2 , sehingga persamaan menjadi:

$$
\begin{aligned}
& \mathrm{A}_{1} \mathrm{~V}_{1}=\mathrm{A}_{2} \mathrm{~V}_{2} \\
& Q_{1}=Q_{2} \\
& \text { Dimana : } \\
& Q=\text { Debit Aliran }\left(\mathrm{m}^{3} / \mathrm{s}\right) \\
& A=\text { Luas Penampang Saluran }\left(\mathrm{m}^{2}\right) \\
& \mathrm{V}=\text { Kecepatan Aliran }\left(\mathrm{m}^{2} / \mathrm{s}\right)
\end{aligned}
$$

\section{b. Persamaan Energi}

Persamaan energi pada aliran dalam pipa dapat dinyatakan dalam:

$\frac{p 1}{\gamma 1}+\frac{V_{1}^{2}}{2 g}+Z_{1}=\frac{p 2}{\gamma 2}+\frac{V_{2}^{2}}{2 g}+Z_{2}+h_{L T} \cdots$

Dimana:

$\mathrm{p}=$ Tekanan $(\mathrm{Pa})$

$\mathrm{Y}=$ Berat Jenis $\left(\mathrm{N} / \mathrm{m}^{3}\right)$

$V=$ Kecepatan Aliran $\left(\mathrm{m}^{2} / \mathrm{s}\right)$

$\mathrm{g}=$ Gravitasi Bumi $\left(\mathrm{m} / \mathrm{s}^{2}\right)$

$\mathrm{Z}=$ Ketinggian $(\mathrm{m})$

$h_{L T}=$ KerugianTekanan Aliran (m)

(Viktor L. Streeter, dkk, 1998)

Persamaan energi dapat diilustrasikan dalam Garis Energi (GE) dan Garis Tingkat Hidrolik (GTH) di bawah ini.

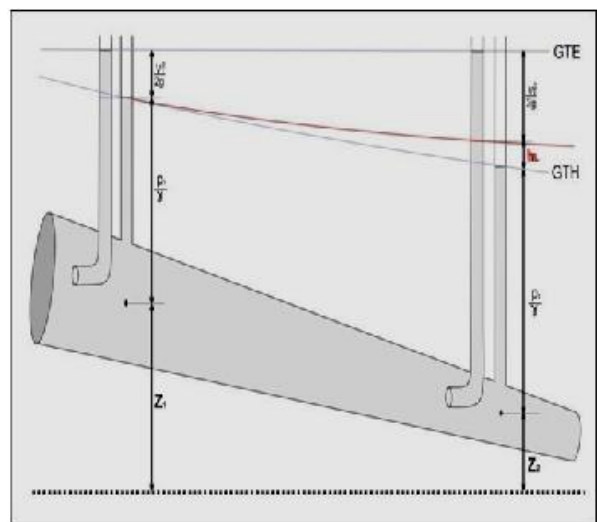

Gambar 1. Garis Energi (GE) dan Garis Tingkat Hidrolik (GTH)

(Sumber: Bruce R. Munson, dkk, 2005)

\section{c. Persamaan Bernoulli}

Persamaan Bernoulli pada aliran fluida dapat dinyatakan dalam:

$$
\frac{p 1}{\gamma 1}+\frac{V_{1}^{2}}{2 g}+Z_{1}=\frac{p 2}{\gamma 2}+\frac{V_{2}^{2}}{2 g}+Z_{2} \ldots \ldots \ldots
$$

Persamaan Bernoulli dengan persamaan energi (persamaan 5) sangat mirip. Perbedaannya yaitu 
pada persamaan Bernoulli mengasumsikan viskositas diabaikan (aliran inviscid), sedangkan untuk persamaan energi, viskositas tidak diabaikan. Selanjutnya efek viskos ini akan menyebabkan kerugian tekanan. (Bruce R. Munson, dkk, 2005)

\section{Kerugian Aliran Fluida}

Di dalam Mekanika Fluida dikenal dua macam Losses yaitu Mayor Losses $\left(h_{f}\right)$ dan Minor Losses $\left(h_{L}\right)$.

a. Mayor Losses $\left(h_{f}\right)$

Mayor losses merupakan kerugian tekanan yang disebabkan oleh gesekan pada dinding-dinding saluran (pipa). Kerugian akibat gesekan ini dapat diketahui menggunakan persamaan DarchyWeibach:

$$
h_{f=} f \frac{L}{D} \frac{V^{2}}{2 g} .
$$

Dimana:

$h_{f}=$ kerugian tekanan $(\mathrm{m})$

$f=$ Koefesien Gesekan

$\mathrm{L}=$ Panjang Saluran $(\mathrm{m})$

$\mathrm{D}=$ Diameter Saluran $(\mathrm{m})$

$\mathrm{V}=$ kecepatan Aliran $(\mathrm{m} / \mathrm{s})$

$\mathrm{g}=$ Gravitasi Bumi $\left(\mathrm{m} / \mathrm{s}^{2}\right)$

b. Minor Losses $\left(h_{L}\right)$

Minor Losses merupakan kerugian yang disebabkan oleh properti disepanjang saluran perpipaan. Properti yang dimaksud berupa katup-katup,

belokan, perubahan dimensi penampang dll. Kerugian akibat Minor Losses ini dinyatakan dalam:

$$
h_{L=} K_{L} \frac{V^{2}}{2 g}
$$

Dimana:

$h_{L}=$ Kerugian Tekanan $(\mathrm{m})$

$K_{L}=$ Koefesien Kerugian

$\mathrm{V}=$ Kecepatan Aliran $(\mathrm{m} / \mathrm{s})$

$\mathrm{g}=$ Percepatan Gravitasi $\left(\mathrm{m} / \mathrm{s}^{2}\right)$

Koefesien kerugian ini berbeda-beda untuk setiap jenis komponen perpipaan. Di bawah ini beberapa jenis komponen perpipaan yang memiliki Koefesien Kerugian yang berbeda-beda.

(Bruce R. Munson, dkk, 2005)

\section{Persamaan Hazen-Williams}

Selain persamaan Darchy-Weybach, dikenal juga persamaan Hazen-Williams. Persamaan Hazen-Williams yang digunakan untuk mencari kerugian tekanan pada sistem perpipaan adalah:

$$
h_{l}=\frac{K_{1} L}{C^{1,85} D^{4,87}} Q^{1,85} \text {. }
$$

\section{Dimana:}

$$
h l=\text { Kerugian Tekanan }(\mathrm{m})
$$

$K_{1}=$ Konstanta (10,59 untuk satuan SI dan 4,72 untuk satuan Inggris)

$\mathrm{C}=$ Koefesien kekasaran HazenWilliams

$\mathrm{L}=$ Panjang pipa $(\mathrm{m})$

$D=$ Diameter pipa $(\mathrm{m})$

$\mathrm{Q}=$ Debit aliran $\left(\mathrm{m}^{3} / \mathrm{s}\right)$ (Merle $\mathrm{C}$. Potter, 2011)

Sedangkan untuk mencari kecepatan adalah:

$$
V=0,354 C I^{0,54} D^{0,63}
$$

Dimana :

$$
\begin{aligned}
\mathrm{V}= & \text { Kecepatan aliran }(\mathrm{m} / \mathrm{s}) \\
\mathrm{C}= & \text { Koefisien kekerasan Hazen } \\
& \text { Williams } \\
\mathrm{D}= & \text { Diameter pipa }(\mathrm{m}) \\
\mathrm{I}= & \text { Kemiringan gradien hidraulik; } \\
& \text { Perbandingan kerugian tekanan } \\
& \text { (Head Loss) dengan panjang } \\
& \text { pipa, sehingga Kemiringan } \\
& \text { gradien hidrolis dapat } \\
& \text { dinyatakan dengan persamaan: }
\end{aligned}
$$

$$
\begin{aligned}
& I=\frac{\mathrm{hl}}{\mathrm{L}} \ldots \ldots \ldots \ldots \ldots \ldots \ldots \ldots \ldots \\
& \text { (Merle C. Potter, 2011) }
\end{aligned}
$$

Tabel 2. Koefesien Kekasaran HazenWilliams

\begin{tabular}{|l|l|}
\hline \multicolumn{1}{|c|}{ Jenis Pipa } & \multicolumn{1}{|c|}{$\begin{array}{c}\text { Koefisien } \\
\text { Kekasaran (C) }\end{array}$} \\
\hline Sangat Halus, Semen Berserat & 140 \\
\hline Besi Cor Baru & 130 \\
\hline Baja Las Baru & 120 \\
\hline $\begin{array}{l}\text { Besi Cor Rata-rata, Baja Ribet } \\
\text { baru }\end{array}$ & 110 \\
\hline $\begin{array}{l}\text { Besi Cor setelah digunakan } \\
\text { Bertahun-tahun }\end{array}$ & $95-100$ \\
\hline Pipa-pipa tua rusak & $60-80$ \\
\hline
\end{tabular}

Sumber: Merle C. Potter, 2011 
C. Dasar-dasar Perancangan Sistem Perpipaan

1. Standar Kebutuhan Air Domestik

Standar kebutuhan air Domestik yaitu kebutuhan air bersih yang digunakan pada tempat- tempat hunian pribadi untuk memenuhi hajat hidup sehari-hari, seperti pemakaian air untuk minum, mandi, dan mencuci. Satuan yang dipakai adalah liter/orang/hari.

Standar kebutuhan domestik ini dapat dilihat pada tabel 2 .

Untuk menghitung jumlah kebutuhan di masing-masing wilayah per detik menggunakan persamaan:

$Q_{S R}=J$ umlah pengguna $x \frac{S K A B}{432000} L / S$.

Dimana:

$\begin{aligned} \mathrm{Q}_{\mathrm{SR}} \quad & \text { Jumlah Kebutuhan } \\ & \text { Sambungan Rumah } \\ & \text { Tangga (L/s) }\end{aligned}$

Jmlh Pengguna $=$ Jumlah total pengguna dalam satu wilayah (Orang)

SKAB

= Standar Kebutuhan Air

sambungan Bersih untuk

Rumah Tangga (L/O/h)

Sedangkan untuk mencari jumlah pengguna adalah dengan cara mengalikan jumlah jiwa per sambungan rumah tangga dengan jumlah Pelanggan (jumlah KK) di wilayah tersebut.

\section{Standar Kebutuhan Air Non Domestik} (ND)

Standar kebutuhan air non domestik yaitu kebutuhan air bersih di luar keperluan rumah tangga. Kebutuhan air non domestik antara lain:

a. Penggunaan komersial dan industri; yaitu penggunaan air oleh badanbadan komersial dan industri-industri.

b. Penggunaan umum; yaitu penggunaan air untuk bangunanbangunan atau fasilitas umum, misalnya rumah sakit, sekolahsekolah, dan rumah ibadah.

Kebutuhan air total di masingmasign wilayah adalah penjumlahan dari pemakaian Sambungan Rumah Tangga (SR), Sambungan Umum dan Kebutuhan Non Domestik (ND), atau dapat digambarkan dengan persamaan:

$$
Q_{\text {Total }}=Q_{S R}+Q_{S U}+Q_{N D}
$$

Dimana:

$$
\begin{aligned}
Q_{\text {Total }}= & \text { Kebutuhan Total }\left(\mathrm{m}^{3} / \mathrm{s}\right) \\
Q_{\mathrm{SR}}= & \text { Kebutuhan Rumah Tangga } \\
& \left(\mathrm{m}^{3} / \mathrm{s}\right) \\
\mathrm{Q}_{\mathrm{SU}}= & \text { Kebutuhan Sambungan } \\
& \text { Umum }\left(\mathrm{m}^{3} / \mathrm{s}\right) \\
\mathrm{Q}_{\mathrm{ND}}= & \text { Kebutuhan Non Domestik } \\
& \left(\mathrm{m}^{3} / \mathrm{s}\right)
\end{aligned}
$$

Table 3. Standar kebutuhan air domestijk

\begin{tabular}{|l|c|c|c|c|c|}
\hline \multirow{2}{*}{ Uraian } & \multicolumn{5}{|c|}{ Kategori Kota Berdasarkan Jumlah } \\
\cline { 2 - 6 } & $\begin{array}{c}\text { Metro } \\
\mathbf{1 . 0 0 0 . 0 0 0}\end{array}$ & $\begin{array}{c}\text { Besar } \\
\mathbf{5 0 0 . 0 0 0} \\
\mathbf{s / d} \\
\mathbf{1 . 0 0 0 . 0 0 0}\end{array}$ & $\begin{array}{c}\text { Sedang } \\
\mathbf{1 0 0 . 0 0 0} \\
\mathbf{s / d} \\
\mathbf{5 0 0 . 0 0 0}\end{array}$ & $\begin{array}{c}\text { Kecil } \\
\mathbf{2 0 . 0 0 0} \\
\mathbf{5} / \mathbf{d} \\
\mathbf{1 0 0 0 0 0}\end{array}$ & $\begin{array}{c}\text { IKK } \\
\text { dan } \\
\text { Desa } \\
<20.000\end{array}$ \\
\hline $\begin{array}{l}\text { Sambungan } \\
\text { rumah tangga } \\
\text { (L/O/h) }\end{array}$ & 190 & 170 & 150 & 130 & 100 \\
\hline $\begin{array}{l}\text { Jumlah jiwa } \\
\text { per SR }\end{array}$ & 5 & 5 & 5 & 5 & 5 \\
\hline $\begin{array}{l}\text { Sambungan } \\
\text { umum (L/O/h) }\end{array}$ & 30 & 30 & 30 & 30 & 30 \\
\hline $\begin{array}{l}\text { Jumlah jiwa } \\
\text { per SU }\end{array}$ & 100 & 100 & 100 & $100-200$ & 200 \\
\hline $\begin{array}{l}\text { Kehilangan } \\
\text { air (\%) }\end{array}$ & $20-30$ & $20-30$ & $20-30$ & $20-30$ & $20-30$ \\
\hline $\begin{array}{l}\text { Faktor jam } \\
\text { puncak }\end{array}$ & $1,75-2,0$ & $1,75-2,0$ & $1,75-2,0$ & 1,75 & 1,75 \\
\hline $\begin{array}{l}\text { Sisa tekan di } \\
\text { penyediaan } \\
\text { air (mka) }\end{array}$ & 10 & 10 & 10 & 10 & 10 \\
\hline Jam operasi & 24 jam & 24 jam & 24 jam & 24 jam & 24 jam \\
\hline
\end{tabular}

Sumber: Ditjen Cipta Karya DPU

Tabel 4. Standar kebutuhan air Non Domestik untuk kategori Kota MetropolitanKota Kecil

\begin{tabular}{|l|l|l|}
\hline \multicolumn{1}{|c|}{ Sektor } & \multicolumn{1}{|c|}{$\begin{array}{c}\text { Nilai } \\
\text { Kebutuhan }\end{array}$} & \multicolumn{1}{c|}{ Satuan } \\
\hline Sekolah & 10 & Liter/murid/hari \\
\hline Rumah Sakit & 200 & Liter/bed/hari \\
\hline Puskesmas & 2.000 & Liter/hari \\
\hline Mesjid & 3.000 & Liter/hari \\
\hline Perkantoran & 10 & Liter/pegawai/hari \\
\hline Pasar & 12.000 & Liter/hektar/hari \\
\hline Hotel & 150 & Liter/bed/hari \\
\hline Rumah Makan & 100 & $\begin{array}{l}\text { Liter/tempat } \\
\text { duduk/hari }\end{array}$ \\
\hline Komplek Militer & 60 & Liter/orang/hari \\
\hline Kawasan Industri & $0,2-0,8$ & Liter/detik/hektar \\
\hline $\begin{array}{l}\text { Kawasan } \\
\text { Pariwisata }\end{array}$ & $0,1-0,3$ & Liter/detik/hektar \\
\hline
\end{tabular}

Sumber: Ditjen Cipta Karya DPU. 
Tabel 5. Standar kebutuhan air Non Domestik untuk kategori IKK/Desa.

\begin{tabular}{|l|l|l|}
\hline \multicolumn{1}{|c|}{ Sektor } & $\begin{array}{c}\text { Nilai } \\
\text { Kebutuhan }\end{array}$ & \multicolumn{1}{c|}{ Satuan } \\
\hline Sekolah & 5 & Liter/murid/hari \\
\hline Mesjid & 3.000 & Liter/Unit/Hari \\
\hline Musholla & 2.000 & Liter/Unit/Hari \\
\hline Rumah Sakit & 200 & Liter/bed/hari \\
\hline Puskesmas & 1.200 & Liter/hari \\
\hline Hotel & 90 & Liter/hari \\
\hline Kawasan Industri & 10 & Liter/hari \\
\hline
\end{tabular}

Sumber: Ditjen Cipta Karya DPU.

\section{METODE PENELITIAN}

\section{A. Teknik Pengumpulan Data}

Pengumpulan data yang diperlukan dilakukan dengan dua cara yaitu dengan cara observasi di lapangan dan meminta data yang diperlukan di instansi terkait yaitu PDAM Lombok Timur.

\section{B. LangkahKerja}

\section{Study Literatur}

Langkah awal yang dilakukan dalam penelitian ini adalah dengan melakukan study literatur mengenai materi-materi yang menunjang dalam penelitian ini. penelitian ini dilakukan berdasarkan keadaan alam dan masyarakat di desa Pemongkong kec. Jerowaru, kab. Lombok Timur.

\section{Survey Lapangan}

Setelah literatur terkumpul, langkah kedua yaitu melakukan survey lapangan dan mengumpulkan data-data yang dibutuhkan. Data-data yang dimaksud adalah:

\section{a. Data Primer}

Data Primer adalah data-data utama yang digunakan dalam perhitungan. Data ini didapatkan dengan cara observasi dilapangan dan meminta data di instansi terkait yaitu PDAM Lombok Timur. Data primer ini berupa:

$>$ Elevasi jaringan

- Panjang pipa

- Diameter pipa

Komponen perpipaan

$>$ Debit terpakai

$>$ Debit tersedia b. Data Skunder

Data Skunder adalah datadata pendukung yang digunakan dalam perhitungan. Data ini juga didapatkan dengan cara observasi dilapangan dan meminta data di instansi terkait yaitu PDAM Lombok Timur. Data Skunder ini berupa:

- Jumlah Pelanggan (konsumen)

> Topografi desa.

> Peta jaringan perpipaan.

\section{Pengolahan dan Analisa Data}

Setelah data-data tersebut diatas didapatkan, Langkah selanjutnya adalah pengolahan data-data untuk digunakan dalam analisa. Analisa data dilakukan dengan perhitungan menggunakan persamaan-persamaan yang didapatkan pada saat study literatur.

\section{Pemodelan dengan Program Epanet} 2.0

Data-data yang telah diolah kemudian digunakan untuk membuat pemodelan berupa simulasi jaringan perpipaan yang ada di desa Pemongkong. Keluaran dari hasil pemodelan ini kemudian dibandingkan dengan hasil perhitungan manual.

\section{HASIL DAN PEMBAHASAN}

A. Hasil Survey Data

1. Pemakaian Air Desa Pemongkong a. Total pemakaian perbulan

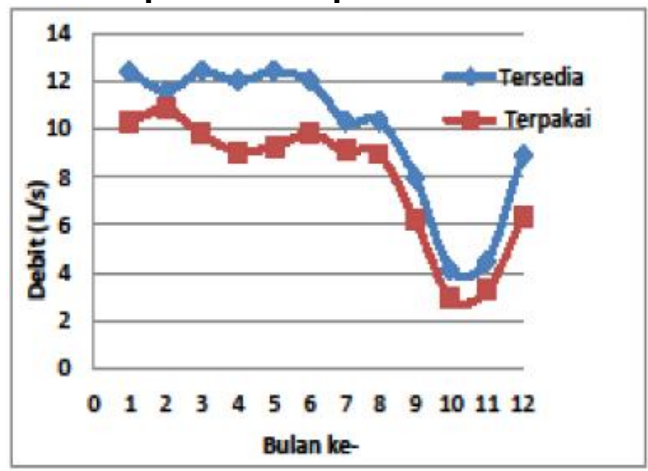

Gambar 2. Grafik perbandingan debit tersedia dan debit terpakai perbulan pada tahun 2012 di desa Pemongkong.

Dari grafik tersebut, dapat dilihat bahwa debit yang tersedia pada bulan ke-1 (Januari) s/d bulan ke-8 (Agustus) masih cukup stabil, dimana debit minimum sebesar $8,96 \mathrm{~L} / \mathrm{s}$ pada bulan Agustus. Debit tersedia mengalami penurunan cukup drastis mulai bulan ke- 
9 (September) s/d bulan ke-12 (Desember). Hal ini menyebabkan pemakaian pada bulan September s/d Desember sangat rendah.

\section{b. Jumlah Pemakaian Perdusun}

Data pemakaian yang digunakan pada penelitian ini adalah data pada bulan Pebruari dan bulan Maret 2012. Data pemakaian pada bulan Pebruari merupakan pemakaian maksimum, sedangkan pada bula Oktober merupakan pemakaian minimum pada Tahun 2012. Data pemakaian air tersebut sudah termasuk data pemakaian Domestik dan Nondomestik.

B. Perbandingan jumlah Kebutuhan dan Pemakaian Rata-rata di Masingmasing Dusun

Jumlah kebutuhan air bersih ini ditentukan berdasarkan Standar Kebutuhan Air Bersih (SKAB) Ditjen Cipta Karya DPU. Berdasarkan SKAB Ditjen Cipta Karya DPU, daerah Pemongkong merupakan daerah yang termasuk dalam kategori desa, sehingga penentuan standar kebutuhan terahadap air bersih akan mengacu pada kategori tersebut.

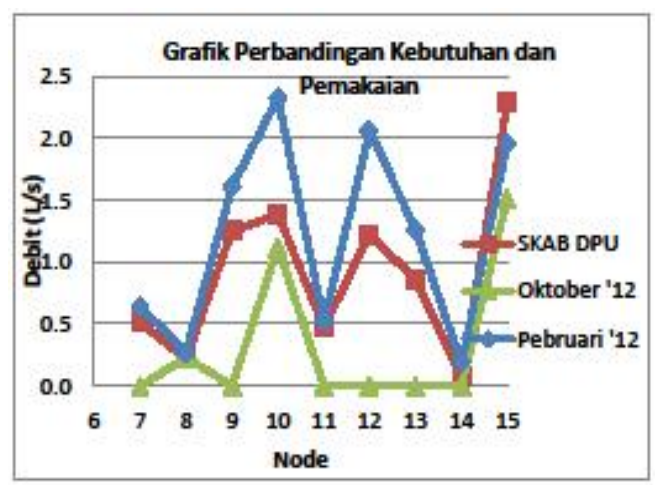

Gambar 3. Grafik perbandingan antara kebutuhan berdasarkan SKAB DPU dengan pemakaian pada bulan Pebruari (maksimum) Oktober (minimum).

Dari gambar 3, dapat dilihat bahwa pada pemakaian maksimum, pemakaian lebih tinggi dari jumlah kebutuhan berdasarkan SKAB DPU. Pada kondisi maksimum ini pemakaian lebih di dominasi oleh node 10 (dusun Serumbung) yaitu sebesar 2,326 L/s. Dominasi pemakaian ini disebabkan oleh jumlah pelanggan yang cukup banyak dan head tekan sisa yang cukup tinggi di node tersebut.

Sedangkan untuk kondisi minimum, pemakaian terjadi hanya di tiga node yaitu node 8 (dusun Pengoros) sebesar $0,228 \mathrm{~L} / \mathrm{s}$, node 10 (dusun Serumbung) sebesar $1,120 \mathrm{~L} / \mathrm{s}$, dan node 15 (desa Sepit) sebesar 1,512 L/s. Hal ini disebabkan karena debit aliran yang tersedia sangat rendah, Sehingga aliran hanya sampai pada tempat yang lebih dekat dari pipa induk.

\section{Analisa di Masing-masing Node}

\section{Berdasarkan SKAB DPU}

Untuk menganalisa masingmasing node, perlu diketahui debit aliran di masing-masing pipa dan node. Debit aliran di masing-masing pipa dapat ditentukan menggunakan persamaan kontinuitas, baik pada pipa tunggal, pipa tersusun seri, pipa tersusun paralel maupun pipa bercabang.

\section{a. Kondisi Biasa (Harian)}

Di bawah ini adalah head tekan sisa di masing-masing dusun berdasarkan SKAB DPU.

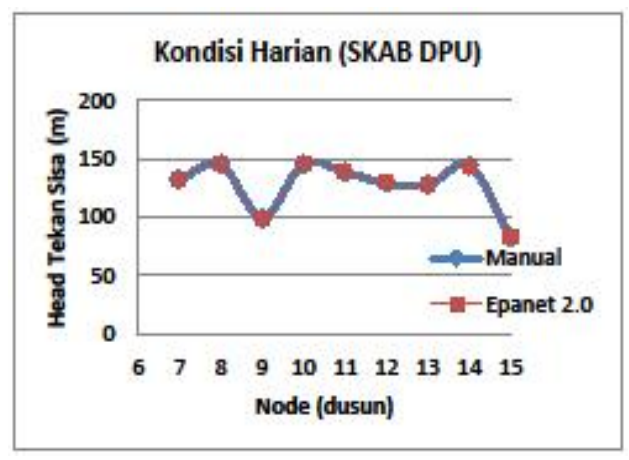

Gambar 4. Grafik head tekan sisa pada kondisi harian berdasarkan SKAB DPU.

Dari hasil analisa tersebut dapat dilihat bahwa tekanan sisa di masing-masing node cukup tinggi. Tekanan sisa minimum terjadi di node 15 (desa Sepit) yaitu berdasarkan analisa manual sebesar $82,66 \mathrm{~m}$ dan berdasarkan simulasi Epanet 2.0 sebesar $82,54 \mathrm{~m}$.

Selanjutnya di desa Pemongkong secara umum tekanan sisa masih di atas $100 \mathrm{~m}$. Nilai ini jauh lebih tinggi dari standar tekanan sisa sebesar $10 \mathrm{~m}$. Hal ini berarti, pada kondisi biasa (harian) sistem perpipaan di desa Pemongkong masih cukup baik untuk menyalurkan air dari sumber ke 
daerah pelayanan.

b. Analisa Jam Puncak

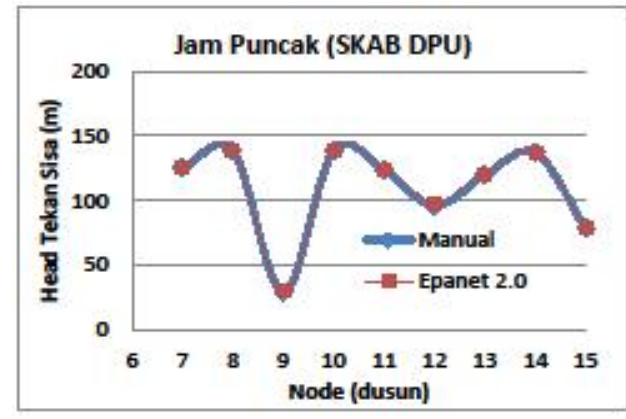

Gambar 5. Grafik head tekan sisa pada jam puncak berdasarkan SKAB DPU.

Dari hasil analisa tersebut dapat dilihat bahwa secara umum tekanan sisa di masing-masing node cukup tinggi. Head tekan sisa minimum terjadi di node 9 (dusun Permas) yaitu berdasarkan analisa manual sebesar 29,23 $\mathrm{m}$ dan berdasarkan simulasi Epanet 2.0 sebesar 29,49 m, node 12 (dusun Ujung) yaitu berdasakan analisa manual sebesar 96,70 $\mathrm{m}$ dan berdasarkan simulasi Epanet sebesar $97,59 \mathrm{~m}$. Hal ini berarti, pada jam puncak kedua node ini memiliki potensi hambatan aliran yang cukup tinggi dibandingkan node-node yang lain, sehingga debit aliran cenderung akan menuju node dimana tekanan sisa yang lebih tinggi.

\section{Berdasarkan Pemakaian Air}

Dengan menggunakan cara yang sama seperti langkah di atas (analisa berdasarkan SKAB DPU), maka didapatkan hasil perhitungan berdasarkan pemakaian air pada bulan Pebruari dan Oktober 2012.

a. Perhitungan Pada Bulan Pebruari 2012

1) Kondisi Biasa (Harian)

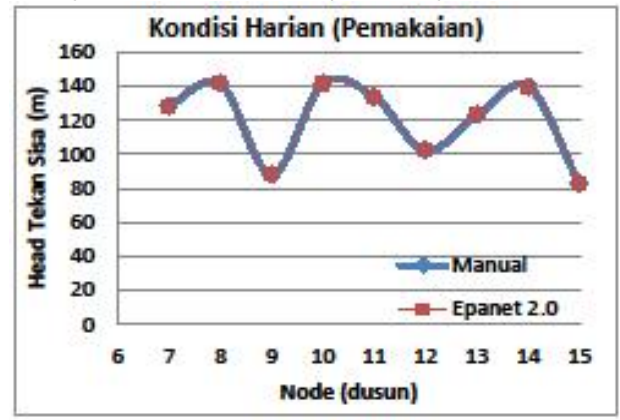

Gambar 6. Grafik head tekan sisa pada kondisi harian berdasarkan pemakaian.
Dari hasil analisa tersebut dapat dilihat bahwa tekanan sisa di masingmasing node cukup tinggi. Tekanan sisa minimum terjadi di node 15 (desa Sepit) yaitu berdasarkan analisa manual sebesar 82,36 $\mathrm{m}$ dan berdasarkan simulasi Epanet 2.0 sebesar 82,28 $\mathrm{m}$ dan node 9 (dusun Permas) yaitu berdasarkan analisa manual sebesar $88,00 \mathrm{~m}$ dan berdasarkan simulasi Epanet 2.0 sebesar 83,52 m. Hal ini berarti, pada kondisi biasa (harian) sistem perpipaan di desa Pemongkong masih cukup baik untuk menyalurkan air dari sumber ke daerah pelayanan.

\section{2) Analisa Jam Puncak}

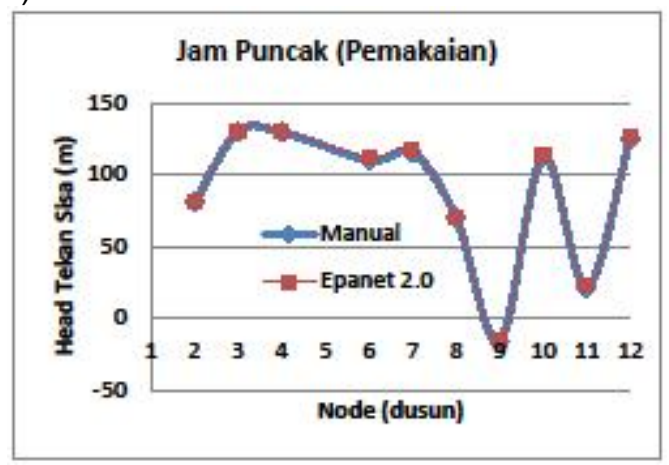

Gambar 7. Grafik head tekan sisa pada jam puncak berdasarkan pemakaian.

Dari hasil analisa tersebut dapat dilihat bahwa terdapat dua node yang memiliki head tekan sisa yang sangat rendah dibandingkan dengan nodenode lain. Kedua node tersebut adalah di node 9 (dusun Permas) yaitu berdasarkan analisa manual sebesar 2,81 $\mathrm{m}$ dan berdasarkan simulasi Epanet 2.0 sebesar $-1,50 \mathrm{~m}$, node 12 (dusun Ujung) yaitu berdasakan analisa manual sebesar 20,15 $\mathrm{m}$ dan berdasarkan simulasi Epanet 2.0 sebesar 21,94 m. Hal ini berarti, pada jam puncak kedua node ini memiliki potensi hambatan aliran yang cukup tinggi dibandingkan node-node yang lain.

b. Perhitungan pada bulan Oktober 2012 Pemakaian pada bulan Oktober 2012 merupakan pemakaian minimum, Sehingga analisa Head Loss pada bulan ini tidak dilakukan. Karena semakin rendah debit aliran dalam suatu saluran pipa, maka Head Loss 
yang terjadi semakin rendah. Jadi analisa Head Loss pada pemakaian maksimum (bulan Pebruari 2012) dapat mewakili analisa pada bulan Oktober 2012.

\section{Solusi untuk Permasalahan}

\section{Permasalahan Ketersediaan Air} Dari hasil analisa dapat diketahui bahwa faktor utama yang menyebabkan terjadinya kekurangan air di desa Pemongkong adalah ketersediaan air di sumber. Kekurangan air ini terutama terjadi pada jam puncak. Untuk mengatasi permasalahan ini dapat dilakukan penampungan-penampungan air di antara sumber dan daerah pelayanan. Hal ini cukup memungkinkan dilakukan karena:

a. Kebutuhan rata-rata harian berdasarkan SKAB sebesar $0,009949 \mathrm{~m}^{3} / \mathrm{s}$ DPU dan berdasarkan jumlah pemakaian maksimum di desa Pemongkong sebesar $0,012997 \mathrm{~m}^{3} / \mathrm{s}$. Sedangkan debit rata-rata yang tersedia di sumber sebesar $0,0124 \mathrm{~m}^{3} / \mathrm{s}$, sehingga debit sisa pada kondisi biasa (harian) masih bisa disimpan untuk digunakan pada jam puncak.

b. Lokasi sumber dan daerah pelayanan cukup jauh, sehingga memungkinkan untuk pembangunan bak penampungan sebanyak mungkin.

\section{Permasalahan Head Tekan Sisa}

Dari hasil analisa, terdapat dua node yang berpotensi menghasilkan head tekan sisa sangat rendah pada jam puncak. Kedua dusun tersebut adalah dusun Permas dan Ujung. Hal ini terjadi karena diameter pipa skunder (transmisi) yang terpasang untuk mendistribusikan air bersih menuju ketiga dusun tersebut adalah 2 in. Sehingga potensi terjadinya head loss cukup tinggi. Masalah ini dapat diatasi dengan cara memperbesar diameter pipa transmisi yang menuju ketiga dusun tersebut. Untuk kondisi pada saat sekarang ini masing memungkinkan untuk memperbesar diameter pipa menjadi 3 in, namun dengan mempertimbangkan pertambahan pelanggan beberapa tahun kemudian, akan lebih baik mengganti pipa dengan diameter 4 in.

\section{PENUTUP}

\section{A. Kesimpulan}

Berdasarkan analisa yang telah dilakukan, kesimpulan yang dapat diambil ialah:

1. Faktor utama yang menyebabkan seringnya terjadi kekurangan air di desa Pemongkong baik secara keseluruhan maupun pada titik-titik tertentu adalah ketersediaan air di sumber.

2. Secara umum, kekurangan air terjadi pada bulan september s/d desamber. Secara khususnya kekurangan air tersebut terjadi pada jam puncak.

3. Terdapat dua dusun yang paling sering mengalami kekurangan air jika dibandingkan dengan dusun lain yaitu, dusun Permas dan dusun Ujung. Hal ini disebabkan karena diameter pipa transmisi yang menuju ketiga dusun tersebut terlalu kecil yaitu sebesar 2 in, sehingga potensi head loss yang menyebabkan kerugian tekanan cukup tinggi.

4. Dari analisa yang telah dilakukan menggunakan analisa manual dengan mengabaikan head loss minor dan analisa menggunakan Epanet 2.0 tanpa mengabaikan head loss minor, dapat diketahui bahwa tidak ada perbedaan yang signifikan antara hasil dari kedua analisa tersebut. Hal ini berarti pada penelitian ini head loss minor tidak begitu berpengaruh dalam menghitung head tekan sisa.

\section{B. Saran}

Bagi teman-teman yang ingin melakukan penelitian selanjutnya dengan topik jaringan perpipaan, jika jaringannya cukup kompleks, analisa sebaiknya hanya menggunakan program komputer, baik Epanet 2.0, WaterNet ataupun WaterCad.

\section{DAFTAR PUSTAKA}

Andika, Rahmad Danu, 2009, Pemodelan sistem Distribusi Jaringan Air Minum, Tugas Ahir, bandung : Institut Teknologi Bandung.

Anonim, 2010, Buku Ajar Sistem Distribusi Air Minum, Institut Teknologi Sepuluh Nopember, Surabaya.

Anonim, 1996, Kriteria Perencanaan Distribusi Air bersih, Ditjen Cipta Karya Dinas Pekerjaan Umum.

Munson, Bruce R., Young, Donald F., Okhiishi, Theodore H., 2005, 
Mekanika Fluida; Jilid 1, Jakarta : Erlangga.

Munson, Bruce R.., Young, Donald F., Okhiishi, Theodore H., 2005, Mekanika Fluida; Jilid 2, Jakarta : Erlangga.

Potter, Merle C., Wiggert, David C., 2011, Schaum's Outlines Mekanika Fluida, Jakarta : Erlangga.
Roberson, Jhon A., Cassidy, Jhon J., Chaudry, M. Hanif, 1997, Hidraulic Enginering; $2^{\text {nd }}$ Edition, USA : Jhon Wiley \& Sons inc.

Streeter, Viktor L., Wylie, E. Benjamin, Bedford, Keith W., 1998, Fluid Mechanic, Singapore : Mc Graw Hill.

Sudrajat S., A., 1983, Mekanika Fluida dan Hidrolika, Bandung : Nova. 